\title{
Health status in COPD cannot be measured by the St George's Respiratory Questionnaire alone: an evaluation of the underlying concepts of this questionnaire
}

\author{
Leonie Daudey ${ }^{1,2^{*}}$, Jeannette B Peters ${ }^{1,2}$, Johan Molema ${ }^{2}$, PN Richard Dekhuijzen ${ }^{2}$, Judith B Prins ${ }^{1}$, \\ Yvonne F Heijdra', Jan H Vercoulen ${ }^{1,2}$
}

\begin{abstract}
Background: Improving patients' health status is one of the major goals in COPD treatment. Questionnaires could facilitate the guidance of patient-tailored disease management by exploring which aspects of health status are problematic, and which aspects are not. Health status consists of four main domains (physiological functioning, symptoms, functional impairment, and quality of life), and at least sixteen sub-domains. A prerequisite for patienttailored treatment is a detailed assessment of all these sub-domains. Most questionnaires developed to measure health status consist of one or a few subscales and measure merely some aspects of health status. The question then rises which aspects of health status are measured by these instruments, and which aspects are not covered. As it is one of the most frequently used questionnaires in COPD, we evaluated which aspects of health status are measured and which aspects are not measured by the St George's Respiratory Questionnaire (SGRQ).
\end{abstract}

Methods: One hundred and forty-six outpatients with COPD participated. Correlations were calculated between the three sections of the SGRQ and ten sub-domains of the Nijmegen Integral Assessment Framework, covering Symptoms, Functional Impairment, and Quality of Life. As the SGRQ was not expected to measure physiological functioning, we did not include this main domain in the statistical analyses. Pearson's $r \geq 0.70$ was used as criterion for conceptual similarity.

Results: The SGRQ sections Symptoms and Total showed conceptual similarity with the sub-domain Subjective Symptoms (main domain Symptoms). The sections Activity, Impacts and Total were conceptual similar to Subjective Impairment (main domain Functional Impairment). The SGRQ sections were not conceptual similar to other subdomains of Symptoms, Functional Impairment, nor to any sub-domain of Quality of Life.

Conclusions: The SGRQ could facilitate the guidance of disease management in COPD only partially. The SGRQ is appropriately only for measuring problems in the sub-domains Subjective Symptoms and Subjective Impairment, and not for measuring problems in other sub-domains of health status, such as Quality of Life.

\section{Background}

COPD is a chronic and debilitating disease and a leading cause of morbidity and mortality worldwide [1]. According to the latest estimates of the World Health Organization (WHO), 210 million people have COPD and 3 million people died of COPD in 2005 [2].

\footnotetext{
* Correspondence: I.daudey@mps.umcn.nl
'Department of Medical Psychology, Radboud University Nijmegen Medical

*Correspondence: I.daudey@mps.umcn.nl
'Department of Medical Psychology, Radboud University Nijmegen Medical Centre, Nijmegen, the Netherlands
}

(c) 2010 Daudey et al; licensee BioMed Central Ltd. This is an Open Access article distributed under the terms of the Creative Commons Attribution License (http://creativecommons.org/licenses/by/2.0), which permits unrestricted use, distribution, and reproduction in any medium, provided the original work is properly cited.

Improving patients' health status is one of the major goals in COPD treatment [3].

Quality of life has become an important endpoint in medical care, but still there is no consensus on the definition of these concepts [4]. Smith and colleagues consider quality of life and health status to be separate constructs, in which quality of life is more related to mental health, whereas health status is more related to physical functioning [4]. The WHO uses a broader 
definition of health status, by defining health status as 'a state of complete physical, mental and social well-being, and not merely the absence of disease or infirmity'. Similarly, others $[5,6]$ define health status as an overall concept covering physiological functioning, symptoms, functional impairment, quality of life, and social functioning as important main domains. These main domains were empirically found to be further divided into sixteen sub-domains $[7,8]$, each sub-domain representing a unique aspect of health status. Despite differences in definitions found in the literature it has become clear that a patient's functioning consists of many conceptually distinct sub-domains. Patient-tailored treatment then requires assessment of all these subdomains.

Questionnaires could facilitate the guidance of patienttailored disease management by exploring which aspects of health status are problematic and which aspects are not. The past decade many questionnaires have been developed to measure health status. However, most of these instruments consists of only one or a few subscales and thus measure merely some aspects of health status. The question then rises which aspects of health status are measured by these instruments, and which aspects are not covered.

The St George's Respiratory Questionnaire (SGRQ), for instance, is one of the most frequently used and translated disease specific health status instruments in COPD [9-11]. A recent Pubmed search gave 555 hits (date 06/03/2010; terms SGRQ and St George's Respiratory Questionnaire). The SGRQ has been developed to allow comparative measurement of health between patient populations and to quantify changes in health following therapy [12]. The SGRQ consists of three sections and a total score: Symptoms, measuring the frequency and severity of respiratory symptoms; Activity, measuring limitation of activities by breathlessness and activities that cause breathlessness; Impacts, measuring disturbances in social and psychological functioning due to airway disease; Total score summarizes the impact of the disease on overall health status [12-14]. The SGRQ thus measures maximally three of the sixteen aspects of health status. It is not clear which aspects of health status are measured, and which aspects of health status are not measured by the SGRQ. This question is all the important to unravel, because the SGRQ, as many other questionnaires, is subject to conceptual confusion. The SGRQ initially was conceived as a standardized selfcompleted questionnaire for measuring health and perceived well-being ('QoL') in airways diseases [12]. In the literature, however, the SGRQ is interchangeably referred to as a measure of quality of life [15], healthrelated quality of life [16], health status [17], a measure for impaired health [18], or a measure of overall impact of the disease [19]. Different terms are used for the concept(s) the SGRQ measures. Additionally, since the SGRQ is often used as a criterion in validity testing of other instruments [20,21], it is essential to clarify which aspects of health status the SGRQ measures.

In the present study, we tested which aspects of health status are measured by the SGRQ in COPD, by comparing the SGRQ sections Symptoms, Activity and Impacts with multiple aspects of the health status domains Symptoms, Functional Impairment and Quality of Life.

\section{Material and methods Subjects}

The 146 subjects took part on a longitudinal study on health status in COPD. Patients were recruited from three different outpatient centres in the Netherlands: Radboud University Nijmegen Medical Centre, Maas Hospital Boxmeer, and Rijnstate Hospital Arnhem. Patients had to fulfil the Global Initiative for Chronic Obstructive Lung Disease (GOLD) criteria of a postbronchodilator $\mathrm{FEV}_{1} \%$ predicted between 30 and 80 percent with a reversibility of obstruction of less than $12 \%$ [1]. Patients suffering from primary co-morbidity or comorbidity that prevented full adherence to the research protocol were excluded, as well as patients with an acute exacerbation, recent ( $<6$ months) participation in a rehabilitation program, or who were not able to speak or read Dutch. One-hundred-and-sixty-eight patients participated in this study. After one year, the assessments were repeated in 146 patients (87\% of included patients in first part). Reasons for dropout were diverse: passed away $(\mathrm{N}=5)$, co-morbidity $(\mathrm{N}=3)$, participation in a rehabilitation programme between the first and second assessments $(\mathrm{N}=2)$, being too busy $(\mathrm{N}=4)$, found participation too exhausting $(\mathrm{N}=3)$, or no transportation $(\mathrm{N}=2)$. For three patients the reasons for dropout were unknown. Data of these 146 patients were used in the present study. The inclusion procedure is described in more detail elsewhere [7]. The study was approved by the Medical Ethics Committee CMO Region ArnhemNijmegen (P02.1411L; CMO-nr 2002/047). Subjects gave informed consent.

\section{Procedures}

Subjects visited the Department of Pulmonary Diseases twice. Physiological assessments were performed and subjects received the Aktometer (accelerometer measuring actual physical activity) [22]. Two weeks later subjects completed questionnaires by the TestOrganiser, a computer program developed by the Department of Medical Psychology and the Department of Instrumental Services of the Radboud University Nijmegen Medical Centre [7]. Questionnaires were presented in the same layout as the paper-and-pencil versions, and a simple 
response board enabled subjects with no prior computer experience to operate the TestOrganiser easily.

\section{Measurements}

Demographic data were recorded. Pulmonary function tests were performed, including transfer capacity for carbon monoxide using the Jaeger masterlab-spirometer according to ERS-criteria [23], and indices of body composition (BodyStat 1997).

\section{St George's Respiratory Questionnaire (SGRQ)}

The SGRQ consists of 50 items with weighted responses divided in three sections - Symptoms, Activity, and Impacts - and a Total score [12-14]. Scores are expressed as percentages of the maximally possible sum of weights. A score of zero represents no health impairment, a score of 100 means maximal health impairment.

\section{Health status main domains Symptoms, Functional Impairment, and Quality of Life}

Health status was measured by the Nijmegen Integral Assessment Framework (NIAF) [7]. The NIAF provides a detailed and empirical definition of health status and covers the domains Physiological Functioning, Symptoms, Functional Impairment, and Quality of Life. These four main domains were found to be subdivided into 15 distinct sub-domains [7]. In another study [8], we found that fatigue was an additional sub-domain. Factor analyses were used to identify underlying concepts in the data. Social Functioning did not emerge as a separate factor, aspects of social functioning were part of the main domains Quality of Life and Functional Impairment. The sub-domains are measured by different existing instruments, and for each sub-domain a Sub-domain Total Score (STS) was calculated. As the SGRQ was not expected to measure physiological functioning, in this study we only evaluated the ten sub-domains of the main domains Symptoms, Functional Impairment, and Quality of Life. See Table 1 for definitions of the subdomains and corresponding instruments.

\section{Statistical Analyses}

The relationships between the sections of the SGRQ and the sub-domains of the NIAF, as well as the intercorrelations of the SGRQ sections, were analyzed by Pearson correlation coefficients. To avoid Type I error due to multiple testing $\mathrm{P}$ was set at 0.01 . A Pearson's $\mathrm{r} \geq 0.70$ was used as criterion for conceptual similarity between the sections of the SGRQ and the sub-domains of the NIAF [24].

\section{Results}

\section{Subjects}

The study sample could be characterized as predominantly male, low educated, and living with a partner
(Table 2). Most subjects were GOLD II/III patients. Some subjects were classified in GOLD I or IV, due to normal variation in $\mathrm{FEV}_{1}$ between the time of the first assessment and second assessment one year later.

\section{Conceptual similarity between sections of the SGRQ and sub-domains of the NIAF}

The SGRQ sections were significantly correlated to many health status aspects, however conceptual similarity $(r \geq 0.70)$ was only reached for two sub-domains of the NIAF (Table 3). The SGRQ sections Symptoms and Total were conceptual similar to the NIAF sub-domain Subjective Symptoms (main domain Symptoms). The SGRQ sections Activity, Impacts, and Total were conceptually similar to the NIAF sub-domain Subjective Impairment (main domain Functional Impairment).

\section{Intercorrelations of the SGRQ sections}

Intercorrelations between the SGRQ sections were moderate to high (Table 4). The SGRQ section Total exceeded the criterion of conceptual similarity with all SGRQ sections $(\mathrm{r} \geq 0.70, \mathrm{p}<0.01)$. The correlation between the sections Impacts and Activity almost reached the criterion of conceptual similarity $(r=0.69$, $\mathrm{p}<0.01)$.

\section{Discussion}

The present study evaluated which aspects of health status are measured by the sections of the SGRQ, and which aspects of health status are not covered by the SGRQ.

The sections of the SGRQ correlated significantly with most sub-domains of the NIAF, indicating that the SGRQ was related to many health status aspects. However, most correlations were low to moderate and well below 0.70 , indicating that shared variance was too low to conclude that sections of the SGRQ were conceptually similar to these sub-domains.

Applying the criterion of conceptual similarity, the SGRQ measured two of the ten evaluated sub-domains of health status. The SGRQ sections Symptoms and Total showed conceptual similarity with the sub-domain Subjective Symptoms (main domain Symptoms), the SGRQ sections Activity, Impacts, and Total showed conceptual similarity with the sub-domain Subjective Impairment (main domain Functional Impairment).

In a previous study [7] we found a high correlation between the sub-domains Subjective Impairment and Subjective Symptoms. The instruments included in these sub-domains were different with respect to the content of the items, but had in common that the itemand-response format required highly subjective and general interpretations by the patient. It was argued that both sub-domains measured highly subjective notions of 
Table 1 Main domains Symptoms, Functional Impairment and Quality of Life of the Nijmegen Integral Assessment Framework

\begin{tabular}{|c|c|c|}
\hline Sub-domain & Definition & Instrument (subscales) \\
\hline \multicolumn{3}{|l|}{ Symptoms } \\
\hline $\begin{array}{l}\text { Subjective } \\
\text { Symptoms }\end{array}$ & $\begin{array}{l}\text { The patient's overall burden of pulmonary } \\
\text { symptoms }\end{array}$ & $\begin{array}{l}\text { PARS-D: Global Dyspnea Activity, Global Dyspnea Burden, Dyspnea } \\
\text { Activity [7]; QoLRiQ: Breathing Problems [33] }\end{array}$ \\
\hline $\begin{array}{l}\text { Dyspnea } \\
\text { Emotions }\end{array}$ & $\begin{array}{l}\text { The level of frustration, depressive feelings, and } \\
\text { anxiety a person } \\
\text { experiences when dyspnoeic }\end{array}$ & DEQ: Frustration, Mood, Anxiety [7] \\
\hline $\begin{array}{l}\text { Expected } \\
\text { Dyspnea }\end{array}$ & $\begin{array}{l}\text { The level of dyspnea that a patients expect to } \\
\text { experience during specific } \\
\text { activities no longer performed }\end{array}$ & PARS-D: Expected Dyspnea [7] \\
\hline Fatigue & The level of experienced fatigue & CIS: Subjective fatigue [34] \\
\hline \multicolumn{3}{|l|}{$\begin{array}{l}\text { Functional } \\
\text { Impairment }\end{array}$} \\
\hline $\begin{array}{l}\text { Actual Physical } \\
\text { Activity }\end{array}$ & $\begin{array}{l}\text { The actual physical activity a patient performs } \\
\text { during two weeks }\end{array}$ & Aktometer (electronic accelerometer) [22] \\
\hline $\begin{array}{l}\text { Behavioral } \\
\text { Impairment }\end{array}$ & $\begin{array}{l}\text { The extent to which a person cannot perform } \\
\text { specific and concrete } \\
\text { activities as a result of having the disease }\end{array}$ & $\begin{array}{l}\text { SIP: Body Care \& Movement, Home Management, Mobility, Ambulation } \\
\text { [35] }\end{array}$ \\
\hline $\begin{array}{l}\text { Subjective } \\
\text { Impairment }\end{array}$ & $\begin{array}{l}\text { The experienced degree of impairment in } \\
\text { general, and in social functioning }\end{array}$ & $\begin{array}{l}\text { QoLRiQ: General Activities, Social Activities [33]; Global Impairment [7]; } \\
\text { SIP: Social Interaction, Burden [35] }\end{array}$ \\
\hline \multicolumn{3}{|l|}{ Quality of Life } \\
\hline $\begin{array}{l}\text { General Quality } \\
\text { of Life }\end{array}$ & $\begin{array}{l}\text { Mood, anxiety, and the satisfaction of a person } \\
\text { with his/her life as a whole }\end{array}$ & $\begin{array}{l}\text { Satisfaction With Life Scale [36] Symptom Check List: Anxiety [37] } \\
\text { BDI: Primary Care [38] }\end{array}$ \\
\hline $\begin{array}{l}\text { Health-related } \\
\text { Quality of Life }\end{array}$ & $\begin{array}{l}\text { Satisfaction related to physiological functioning } \\
\text { and the future }\end{array}$ & Satisfaction Physiological Functioning, Satisfaction Future [7] \\
\hline $\begin{array}{l}\text { Satisfaction } \\
\text { Relations }\end{array}$ & $\begin{array}{l}\text { Satisfaction with the (absent) relationships with } \\
\text { spouse and others }\end{array}$ & Satisfaction Spouse, Satisfaction Social [7] \\
\hline
\end{tabular}

PARS-D: Physical Activity Rating Scale-Dyspnea; QoLRiQ: Quality of Life for Respiratory Illness Questionnaire; DEQ: Dyspnea Emotions Questionnaire; CIS: Checklist Individual Strength; SIP: Sickness Impact Profile; BDI, Beck Depression Inventory

'being ill', also referred to as illness perceptions [25]. As the SGRQ reached the criterion for conceptual similarity with these two sub-domains, this would imply that the SGRQ in fact measures illness perceptions, related to symptoms (section Symptoms and Total) and functional impairment (sections Activity and Impacts). This conclusion is underlined by the high intercorrelations between the SGRQ sections, some correlations even exceeding the criterion for conceptual similarity.

Although illness perceptions related to symptoms and functional impairment are very relevant concepts, many other important aspects of health status are not covered by the SGRQ. With respect to the SGRQ as a measure of aspects of symptoms, these are restricted to the subjectively experienced severity of pulmonary symptoms. Other important aspects of symptoms, such as dyspnea-related emotions, are not measured specifically. With respect to functional impairment, only the subjectively experienced impairments are measured by the SGRQ. Impairment on the behavioural level or actual physical activity level is not measured by the SGRQ sections. Furthermore, the present study showed that the SGRQ does not measure any of the three subdomains of quality of life evaluated in this study (General Quality of Life, Health-related Quality of Life, and
Satisfaction Relation). Finally, since the SGRQ measures merely two sub-domains of the ten evaluated sub-domains, the SGRQ does not provide a detailed measurement of health status. Similarly, present data show that the SGRQ should be considered a valid measure of impaired health in COPD, as the SGRQ originally was conceived. However, the SGRQ measures only two aspects of impaired health (subjective symptoms and subjective impairment). To measure all aspects of impaired health, and thereby allowing patient-tailored treatment, other instruments need to be included as well.

Some methodological issues need to be addressed. First, the NIAF is not the definite answer to the problem of conceptual confusion in current health status instruments. Other aspects of health status not included in the framework may be relevant to COPD patients. This needs to be addressed in future studies, in which patient feedback should be incorporated. Nevertheless, this framework does provide a much more detailed definition of health status, as expressed by the many subdomains, and is much more formulated in terms of empirical observations than found in the literature. Each sub-domain represents a (conceptually) unique health status aspect. At least 16 sub-domains are measured to 
Table 2 Demographic, clinical data, and data of the St George's Respiratory Questionnaire of participating COPD patients

\begin{tabular}{|c|c|}
\hline Variable & Mean \pm SD \\
\hline Male sex \% & 76.7 \\
\hline Age (years) & $65.8 \pm 9.0$ \\
\hline \multicolumn{2}{|l|}{ Education \% } \\
\hline Low & 48.6 \\
\hline Middle & 29.5 \\
\hline High & 19.9 \\
\hline \multicolumn{2}{|c|}{ Personal situation \% } \\
\hline Partner & 77.8 \\
\hline Divorced & 6.3 \\
\hline Widowhood & 8.3 \\
\hline Single & 7.6 \\
\hline \multicolumn{2}{|c|}{ Cigarette smoking \% } \\
\hline Current & 41.8 \\
\hline Former & 45.9 \\
\hline Never & 11.0 \\
\hline $\mathrm{BMI}\left(\mathrm{kg} / \mathrm{m}^{2}\right)$ & $25.9 \pm 4.1$ \\
\hline $\mathrm{FEV}_{1}(\mathrm{~L})$ & $1.6 \pm 0.5$ \\
\hline $\mathrm{FEV}_{1} \%$ predicted & $53.6 \pm 13.9$ \\
\hline $\mathrm{FEV}_{1} /$ FVC \% & $44.0 \pm 11.4$ \\
\hline TLC \% predicted & $103.7 \pm 14.6$ \\
\hline RV \% predicted & $128.3 \pm 30.3$ \\
\hline $\mathrm{TL}_{\mathrm{CO}} \%$ predicted & $62.3 \pm 21.5$ \\
\hline \multicolumn{2}{|l|}{ GOLD \% } \\
\hline । & 2.1 \\
\hline$\|$ & 58.9 \\
\hline III & 34.2 \\
\hline IV & 4.8 \\
\hline \multicolumn{2}{|l|}{ SGRQ section } \\
\hline Symptoms & $40.9 \pm 24.8$ \\
\hline Activity & $40.9 \pm 21.8$ \\
\hline Impacts & $20.2 \pm 13.5$ \\
\hline Total & $30.2 \pm 15.4$ \\
\hline
\end{tabular}

Data are presented as mean \pm SD unless otherwise indicated. Percentages may not add up to 100 due to missing data (three patients with no specified education, two patients with no specified smoking habits). BMI: body mass index; $\mathrm{FEV}_{1} \%$ predicted: forced expiratory volume in one second as percentage predicted; $\mathrm{FEV}_{1} / \mathrm{FVC} \%$ : forced expiratory volume/forced vital capacity; TLC: total lung capacity; TLC \% predicted: total lung capacity as percentage predicted; RV: residual volume; RV: residual volume as percentage predicted; $\mathrm{TL}_{\mathrm{CO}} \%$ predicted: transfer capacity (of lung) for carbon monoxide as percentage predicted; GOLD: Global Initiative for Chronic Obstructive Lung Disease; SGRQ: St George's Respiratory Questionnaire.

provide a detailed picture of the health status of a COPD patient.

Second, using the criterion of conceptual similarity ( $\mathrm{r}$ $\geq 0.70$ ) as a standard for validity seems a very strict criterion. However, considering the conceptual confusion in health status, one must be carefully interpreting results of earlier validity studies. Often, much lower correlations are accepted as evidence for the validity of the instrument under scrutiny. For example, a correlation between two instruments of 0.40 may be statistically significant, but it indicates only $16 \%$ of shared variance. Unambiguous conclusions concerning conceptual similarity between two instruments can only be drawn from the results using a strict approach.

The present study focuses on the relationships between the SGRQ sections and the main domains Symptoms, Functional Impairment, and Quality of Life. Therefore, the conclusions of the present study are not applicable with respect to physiological functioning. However, from a theoretical point of view it is unlikely that a questionnaire will provide a direct measure of physiological processes. For example, studies to date $[26,27]$ often show a relationship between $\mathrm{FEV}_{1}$ and the SGRQ. However, these correlations are low to moderate and do not exceed the criterion of conceptual similarity.

With respect to generalizability of the present study, we believe that the present sample may be an adequate reflection of a the Dutch population of patients with COPD seen in an outpatient clinic. This sample may however not be representative for subgroups of COPD such as patients in pulmonary rehabilitation or patients with primary co-morbidity, which were two major exclusion criteria.

An important clinical implication of the present study is that the SGRQ could facilitate the guidance of disease management only partially. The SGRQ can only be used appropriately for exploring problems in the sub-domains Subjective Symptoms and Subjective Impairment, and not for exploring problems in other sub-domains of health status, such as aspects of quality of life.

Most instruments claiming to measure specific aspects of health status contain only two to five subscales. Thus, at best only some aspects of health status are measured by a specific instrument. This not only has implications for clinical practice, but also for research purposes. In pharmacological trials, the drug under study may have beneficial effects on some aspects of health status, but not on other aspects. If the instruments used measure only few aspects of health status beneficial effects may be missed. With respect to the use of instruments in clinical practice, the present results indicate that one single instrument cannot provide sufficient information on a patient's health status to effectively tailor treatment to the needs of the individual patient, since measuring all aspects of health status is a prerequisite for patienttailored treatment. This requires combining different instruments into a battery of instruments measuring multiple aspects of health status. However, implementing instruments in daily practice to facilitate disease management requires that instruments are not too time consuming. The past decade a few short instruments have been developed specifically to allow measurement of health status aspects in routine care, such as the 
Table 3 Correlations between the St George's Respiratory Questionnaire and the Nijmegen Integral Assessment Framework $^{\#}$

\begin{tabular}{|c|c|c|c|c|}
\hline & \multicolumn{4}{|c|}{ St George's Respiratory Questionnaire } \\
\hline & Symptoms & Activity & Impacts & Total \\
\hline \multicolumn{5}{|c|}{ Nijmegen Integral Assessment Framework } \\
\hline \multicolumn{5}{|l|}{ Symptoms } \\
\hline Subjective Symptoms & $0.70^{\natural}$ & 0.64 & 0.60 & $0.74^{n}$ \\
\hline Dyspnea Emotions & 0.25 & 0.31 & 0.32 & 0.35 \\
\hline Dyspnea Expected & 0.43 & 0.59 & 0.43 & 0.57 \\
\hline Fatigue & 0.47 & 0.57 & 0.60 & 0.65 \\
\hline \multicolumn{5}{|l|}{ Functional Impairment } \\
\hline Actual Physical Activity & - & 0.42 & 0.31 & 0.34 \\
\hline Behavioral Impairment & 0.28 & 0.65 & 0.54 & 0.61 \\
\hline Subjective Impairment & 0.67 & 0.70 & 0.71 & 0.81 \\
\hline \multicolumn{5}{|l|}{ Quality of Life } \\
\hline General Quality of Life & 0.50 & 0.46 & 0.52 & 0.57 \\
\hline Health-related Quality of Life & 0.43 & 0.42 & 0.46 & 0.51 \\
\hline Satisfaction Relations & 0.24 & - & - & 0.21 \\
\hline
\end{tabular}

\#only significant correlations ( $p<0.01$ ) are shown; "Pearson's $r \geq 0.70$ (criterion for conceptual similarity)

Clinical COPD Questionnaire [28], the Respiratory Illness Questionnaire-monitoring 10 [29], and the EuroQoL [30]. None of these instruments provide a detailed picture of a patient's health status. Recently, we developed the Nijmegen Clinical Screening Instrument (NCSI), an instrument which can be used in routine care [31]. The NCSI is based on the NIAF and measures eleven sub-domains of physiological functioning, symptoms, functional impairment, and quality of life. The NCSI enables a quick (15-25 minutes) and detailed assessment of health status. Also, the COPD Assessment Test (CAT) was developed [32], 'a validated short and simple instrument for assessing the impact of COPD on health status'. The CAT is constructed as a uni-dimensional instrument, i.e. measuring one single concept, as expressed in a single score. In addition, the correlation between the CAT and the SGRQ-C was well above the criterion for conceptual similarity $(r=0.80)$ [32]. Taken together, it is very likely that the CAT, like the SGRQ, measures illness perceptions. How important illness perceptions may be, patient-tailored treatment requires a detailed assessment of many aspects of health

Table 4 Intercorrelations between sections of the St George's Respiratory Questionnaire ${ }^{\#}$

\begin{tabular}{lllll}
\hline \multicolumn{5}{c}{ St George's Respiratory Questionnaire } \\
\hline & Symptoms & Activity & Impacts & Total \\
\hline Symptoms & 1.00 & - & - & - \\
Activity & 0.50 & 1.00 & - & - \\
Impacts & 0.54 & 0.69 & 1.00 & - \\
Total & $0.73^{\natural}$ & $0.88^{q}$ & $0.91^{\natural}$ & 1.00 \\
\hline
\end{tabular}

"only significant correlations $(p<0.01)$ are shown; "Pearson's $r \geq 0.70$ (criterion for conceptual similarity) status. Therefore, the CAT also will have limited value in patient-tailored treatment.

\section{Conclusions}

Detailed measurement of health status in patients with COPD is a prerequisite for patient-tailored treatment. However, carefulness should be noted when selecting instruments to measure health status, because most instruments measure only a few aspects of health status. The SGRQ can only be used appropriately for measuring problems in the sub-domains Subjective Symptoms and Subjective Impairment, and not for measuring problems in other sub-domains of health status, such as aspects of Quality of Life. Different instruments should be combined to provide a detailed picture of a patient's health status.

\section{Acknowledgements}

We are indebted to Dr. F. van den Elshout (pulmonologist, Rijnstate Hospital, Arnhem) and Dr. R. Bunnik (pulmonologist, Maas Hospital, Boxmeer) for their contribution in the patient recruitment and the multidisciplinary Taskforce Assessment of the Department of Pulmonary Rehabilitation for their invaluable contributions to the development of the conceptual models. The study was supported by grants of the Dutch Asthma Foundation and GlaxoSmithKline.

\section{Author details}

${ }^{1}$ Department of Medical Psychology, Radboud University Nijmegen Medical Centre, Nijmegen, the Netherlands. ${ }^{2}$ Department of Pulmonary Diseases, Radboud University Nijmegen Medical Centre, Groesbeek, the Netherlands.

\section{Authors' contributions}

LD participated in the design of the study, the acquisition of the data, performed statistical analyses and interpreted the data, and drafted the manuscript. JBPe participated in the acquisition of the data, and in the critical revision of the manuscript for important intellectual content. JM participated in the design of the study, the acquisition of the data, and in the critical revision of the manuscript for important intellectual content. PNRD participated in the critical revision of the manuscript for important 
intellectual content. JBPr participated in the critical revision of the manuscript for important intellectual content. YFH participated in the acquisition of the data, and the critical revision of the manuscript for important intellectual content. JHV conceived the study, participated in its design and coordination and helped to draft the manuscript. All authors read and approved the final manuscript.

\section{Competing interests}

The authors declare that they have no competing interests.

Received: 12 January 2010 Accepted: 22 July 2010

Published: 22 July 2010

\section{References}

1. Celli BR, MacNee W: Standards for the diagnosis and treatment of patients with COPD: a summary of the ATS/ERS position paper. Eur Respir J 2004, 23:932-946.

2. World Health Organization. [http://www.who.int/respiratory/copd/en/].

3. Executive Summary: Global Strategy for Diagnosis, Management, and Prevention of Chronic Obstructive Pulmonary Disease - Update December 2009. [http://www.goldcopd.org//Guidelineitem.asp? $|1=2 \&| 2=1 \&$ intld $=2180]$

4. Smith KW, Avis NE, Assmann SF: Distinguishing between quality of life and health status in quality of life research: a meta-analysis. Qual Life Res 1999, 8:447-459.

5. Wilson IB, Cleary PD: Linking clinical variables with health-related quality of life. A conceptual model of patient outcomes. JAMA 1995, 273:59-65.

6. Taillefer M, Dupuis G, Roberge M, Le May S: Health-related quality of life models: Systematic review of the literature. Social Indicators Research 2003, 64:293-323.

7. Vercoulen JH, Daudey L, Molema J, Vos PJ, Peters JB, Top M, Folgering H: An Integral assessment framework of health status in chronic obstructive pulmonary disease (COPD). Int J Behav Med 2008, 15:263-279.

8. Peters JB, Heijdra YF, Daudey L, Molema J, Dekhuijzen PNR, Vercoulen JH: Prevalence and severity of fatigue and its relationships with dyspnea and health status in COPD patients [abstract]. Am J Respir Crit Care Med 2007, 175:A642.

9. Barr JT, Schumacher GE, Freeman S, LeMoine M, Bakst AW, Jones PW: American translation, modification, and validation of the St. George's Respiratory Questionnaire. Clin Ther 2000, 22:1121-1145.

10. Chan SL, Chan-Yeung MM, Ooi GC, Lam CL, Cheung TF, Lam WK, Tsang KW: Validation of the Hong Kong Chinese version of the St. George Respiratory Questionnaire in patients with bronchiectasis. Chest 2002, 122:2030-2037.

11. Bourbeau J, Maltais F, Rouleau M, Guimont C: French-Canadian version of the Chronic Respiratory and St George's Respiratory questionnaires: an assessment of their psychometric properties in patients with chronic obstructive pulmonary disease. Can Respir J 2004, 11:480-486.

12. Jones PW, Quirk FH, Baveystock CM: The St-George Respiratory Questionnaire. Respiratory Medicine 1991, 85:25-31.

13. Jones PW, Quirk FH, Baveystock CM, Littlejohns P: A self-complete measure of health status for chronic airflow limitation. The St. George's Respiratory Questionnaire. Am Rev Respir Dis 1992, 145:1321-1327.

14. Jones PW, Spencer S, Adie S: The St George's Respiratory Questionnaire Manual. London 2003.

15. Okubadejo AA, Paul EA, Jones PW, Wedzicha JA: Does long-term oxygen therapy affect quality of life in patients with chronic obstructive pulmonary disease and severe hypoxaemia? Eur Respir J 1996 9:2335-2339.

16. Nishiyama O, Taniguchi H, Kondoh Y, Nishimura K, Suzuki R, Takagi K, Yamaki $\mathrm{K}$ : The effectiveness of the visual analogue scale 8 in measuring health-related quality of life for COPD patients. Respir Med 2000, 94:1192-1199.

17. Vestbo J, Soriano JB, Anderson JA, Calverley P, Pauwels R, Jones P: Gender does not influence the response to the combination of salmeterol and fluticasone propionate in COPD. Respir Med 2004, 98:1045-1050.

18. Wilson CB, Jones PW, O'Leary CJ, Cole PJ, Wilson R: Validation of the St. George's Respiratory Questionnaire in bronchiectasis. Am J Respir Crit Care Med 1997, 156:536-541.

19. Jones PW: Health status measurement in chronic obstructive pulmonary disease. Thorax 2001, 56:880-887.
20. Stallberg B, Nokela M, Ehrs PO, Hjemdahl P, Wikstrom JE: Validation of the Clinical COPD Questionnaire in primary care. Health Qual Life Outcomes 2009, 7:26.

21. Camelier A, Rosa FW, Jones PW, Jardim JR: Brazilian version of airways questionnaire 20: a reproducibility study and correlations in patients with COPD. Respir Med 2005, 99:602-608.

22. Vercoulen JHMM, Bazelmans E, Swanink CMA, Fennis JFM, Galama JMD, Jongen PJH, Hommes OR, van der Meer JWM, Bleijenberg G: Physical activity in chronic fatigue syndrome: assessment and its role in fatigue. $J$ Psychiat Res 1997, 31:661-673.

23. Tammeling GJ, Quanjer PH: Standardized lung function testing. Eur Respir J 1993, 6:5-33

24. Ogden J: Theory and measurement: conceptualisation, operationalisation, and the example of health status. Assessment in Behavioral Medicine East Sussex: Brunner-RoutledgeVingerhoets A 2001, 73-90.

25. Scharloo M, Kaptein AA, Weinman J, Hazes JM, Willems LN, Bergman W, Rooijmans HG: Illness perceptions, coping and functioning in patients with rheumatoid arthritis, chronic obstructive pulmonary disease and psoriasis. J Psychosom Res 1998, 44:573-585.

26. Madueno A, Martin A, Peculo JA, Anton E, Paravisini A, Leon A: Usefulness of inspiratory capacity measurement in COPD patients in the primary care setting. Int J Gen Med 2009, 2:219-225.

27. Pereira ED, Pinto R, Alcantara M, Medeiros M, Mota RM: Influence of respiratory function parameters on the quality of life of COPD patients. $J$ Bras Pneumol 2009, 35:730-736.

28. Van Der Molen T, Willemse BW, Schokker S, Ten Hacken NH, Postma DS, Juniper EF: Development, validity and responsiveness of the Clinical COPD Questionnaire. Health Qual Life Outcomes 2003, 1:13.

29. Jacobs JE, Maille AR, Akkermans RP, van Weel C, Grol RPTM: Assessing the quality of life of adults with chronic respiratory diseases in routine primary care: Construction and first validation of the 10-Item Respiratory Illness Questionnaire-monitoring 10 (RIQ-MON10). Qual Life Res 2004, 13:1117-1127.

30. EuroQol-a new facility for the measurement of health-related quality of life. The EuroQol Group. Health Policy 1990, 16:199-208.

31. Peters JB, Daudey L, Heijdra YF, Molema J, Dekhuijzen PN, Vercoulen JH: Development of a battery of instruments for detailed measurement of health status in patients with COPD in routine care: the Nijmegen Clinical Screening Instrument. Qual Life Res 2009, 18:901-912.

32. Jones PW, Harding G, Berry P, Wiklund I, Chen WH, Kline LN: Development and first validation of the COPD Assessment Test. Eur Respir J 2009, 34:648-654.

33. Maillé AR, Koning CJ, Zwinderman AH, Willems LN, Dijkman JH, Kaptein AA: The development of the 'Quality-of-life for Respiratory Illness Questionnaire (QOL-RIQ)': a disease-specific quality-of-life questionnaire for patients with mild to moderate chronic non-specific lung disease. Respir Med 1997, 91:297-309.

34. Vercoulen JHMM, Swanink CMA, Galama JMD, Fennis JFM, van der Meer JWM, Bleijenberg G: Dimensional assessment in chronic fatigue syndrome. J Psychosom Res 1994, 38:383-392.

35. Bergner M, Bobbitt RA, Carter WB, Gilson BS: The Sickness Impact Profile: development and final revision of a health status measure. Med Care 1981, 19:787-805.

36. Diener E, Emmons RA, Larsen RJ, Griffin S: The satisfaction with life scale. Journal of Personality Assessment 1985, 49:71-75.

37. Arrindell WA, Ettema JHM: SCL-90: Handleiding bij een multidimensionele psychopathologie-indicator [SCL-90: Manual for a multifaceted measure of psychopathology] Lisse: Swets \& Zeitlinger 1986.

38. Beck AT, Guth D, Steer RA, Ball R: Screening for major depression disorders in medical inpatients with the Beck Depression Inventory for Primary Care. Behav Res Ther 1997, 35:785-791.

\section{doi:10.1186/1465-9921-11-98}

Cite this article as: Daudey et al:: Health status in COPD cannot be measured by the St George's Respiratory Questionnaire alone: an evaluation of the underlying concepts of this questionnaire. Respiratory Research 2010 11:98. 